九州大学学術情報リポジトリ

Kyushu University Institutional Repository

\title{
Novel solid-state manganese oxide-based reference electrode for YSZ-based oxygen sensors
}

Miura, Norio

Art, Science and Technology Center for Cooperative Research, Kyushu University

Jin, Han

Interdisciplinary Graduate School of Engineering Sciences, Kyushu University

Wama, Ryotaro

Tokuyama Corp | Interdisciplinary Graduate School of Engineering Sciences, Kyushu University

Nakakubo, Shouhe i

Kobe Steel Ltd | Interdisciplinary Graduate School of Engineering Sciences, Kyushu University 他

http://hdl. handle. net/2324/25467

出版情報：Sensors and Actuators，B：Chemical. 152 (2)，pp.261-266，2011-03-01. Elsevier バージョン：

権利関係: (C) 2010 Elsevier B.V. 
Novel Solid-State Manganese Oxide-based Reference Electrode for YSZ-based Oxygen Sensors

\author{
Norio Miura, ${ }^{\mathrm{a}, *}$ Han Jin, ${ }^{\mathrm{b}}$ Ryotaro Wama, ${ }^{\mathrm{b}, 1}$ Shouhei Nakakubo, ${ }^{\mathrm{b}, 2}$ Perumal Elumalai, ${ }^{\mathrm{a},} 3$ \\ and Vladimir V. Plashnitsa ${ }^{\mathrm{c}}$ \\ ${ }^{a}$ Art, Science and Technology Center for Cooperative Research, Kyushu University, \\ Kasuga-shi, Fukuoka 816-8580, Japan \\ ${ }^{b}$ Interdisciplinary Graduate School of Engineering Sciences, Kyushu University, \\ Kasuga-shi, Fukuoka 816-8580, Japan \\ ${ }^{\mathrm{c}}$ Research and Education Center of Carbon Resources, Kyushu University \\ Kasuga-shi, Fukuoka 816-8580, Japan
}

*Corresponding author. Tel: +81-92-583-8852; Fax: +81-92-583-8976

E-mail address: miurano@astec.kyushu-u.ac.jp (N. Miura)

Present addresses:

${ }^{1}$ Tokuyama Corp., Tsukuba-shi, Ibaraki 300-4247, Japan (R. Wama).

${ }^{2}$ Kobe Steel Ltd., Kobe-shi, Hyogo 651-2271, Japan (S. Nakakubo).

${ }^{3}$ Department of Materials Science, School of Chemistry, Madurai Kamaraj University, Madurai, Tamilnadu 625021, India (P. Elumalai). 


\begin{abstract}
Various Mn-based oxides have been screened to find a suitable all-solid-state gas-insensitive reference-electrode (RE) for yttria-stabilized zirconia (YSZ)-based potentiometric oxygen sensor. The experimental observation of tubular YSZ-based sensors attached with each of the outer Mn-based oxide sensing electrodes (SEs) and the inner Pt-RE revealed that $\mathrm{Mn}_{2} \mathrm{O}_{3}-\mathrm{SE}$ was insensitive to all gases including oxygen at operating temperatures below $550^{\circ} \mathrm{C}$. Thus, the planar-like rod-type YSZ-based sensor using Pt-SE, Au-SE and $\mathrm{Mn}_{2} \mathrm{O}_{3}-\mathrm{RE}$ was then fabricated and its sensing performances were evaluated at $550^{\circ} \mathrm{C}$. As a result, the planar sensor using a couple of Pt-SE and $\mathrm{Mn}_{2} \mathrm{O}_{3}-\mathrm{RE}$ exhibited excellent responses to oxygen in the concentration range of $0.05-21$ vol.\% obeying Nernst equation and gave negligible responses to other co-existing gases. Close similarity of the results for tubular and planar sensors operated in a wide range of air/fuel $(\mathrm{A} / \mathrm{F})$ ratio indicated that the tubular YSZ-based sensor using the inner Pt-RE could be successfully miniaturized to the planar one using $\mathrm{Mn}_{2} \mathrm{O}_{3}-\mathrm{RE}$ without sacrificing its performance.
\end{abstract}

Keywords: Oxygen sensor; Solid reference electrode; YSZ; $\mathrm{Mn}_{2} \mathrm{O}_{3}$ 


\section{Introduction}

Nowadays, the emission of automobile's exhaust causes about $30 \%$ of the total ambient air-pollution [1]. To reduce the exhaust emission and improve the fuel efficiency, the directinjection-type gasoline engines (GDEs) have been recently introduced. In these engines, an on-board diagnosis (OBD) system has been proposed to monitor all the gaseous components related to air pollution. The OBD system is equipped with a conventional three-way catalyst (TWC) which oxidizes $\mathrm{CO}$ and hydrocarbons (HCs) into $\mathrm{CO}_{2}$ and $\mathrm{H}_{2} \mathrm{O}$ under lean burn (air rich) condition and/or at stoichiometric air/fuel (A/F) ratio and reduces $\mathrm{NO}_{\mathrm{x}}$ into $\mathrm{N}_{2}$ at stoichiometric $\mathrm{A} / \mathrm{F}$ ratio and/or under rich burn (air lean) condition [2, 3]. Thus, the performance of TWC is maximized in the exhaust gas condition close to the stoichiometric point $(\mathrm{A} / \mathrm{F} \cong 14.7$ for a gasoline engine $)$. In this regard, the primary roles of OBD system are (i) to monitor TWC efficiency and (ii) to detect possible TWC deterioration and failure. For the purpose of attaining the roles, two identical oxygen sensors ( $\lambda$ sensors) are currently used: one is placed upstream of the TWC to control A/F ratio and another one is located downstream of TWC to monitor the efficiency of catalytic converter.

From the standpoint of their operational principle, oxygen sensors for automotive use are classified into three main groups: (i) potentiometric type, (ii) amperometric limiting-current type and (iii) resistive type [4-9]. Most widely utilized A/F sensors are yttria-stabilized zirconia (YSZ)-based potentiometric sensors, due to its stable, accurate and reproducible sensing performance even under harsh environment $[6-8,10]$. The most-commonly utilized thimble-type YSZ-based oxygen sensors are configured in a tubular geometry, where an outer Pt-sensing electrode (SE) is exposed to exhaust gas and an inner Pt-reference electrode (hereinafter called Pt/air-RE) is exposed to an ambient atmospheric air ( 21 vol.\% $\left.\mathrm{O}_{2}\right)$. The use of Pt/air-RE is even prevailing in Bosch's simplified laminated-type oxygen sensor [6]. In 
these cases, the concentration of oxygen in exhaust gas can be calculated based on the following Nernst equation:

$$
E=\frac{R T}{n F} \ln \frac{p_{\mathrm{O}_{2}(\text { exhaust })}}{p_{\mathrm{O}_{2}(\text { air })}}
$$

where $\mathrm{E}$ is electromotive force (emf), $\mathrm{R}$ is universal gas constant, $\mathrm{F}$ is Faraday's constant, $\mathrm{T}$ is absolute temperature and $p_{\mathrm{O}_{2}}$ is partial pressure of oxygen. This indicates that $\mathrm{Pt} / \mathrm{air}-\mathrm{RE}$ is always necessary in the presently-used oxygen sensors. Thus, the sensor's configuration is not so simple and is rather difficult to be miniaturized.

In a view of simplification and miniaturization of sensor's structure, there is a strong necessity to find an alternative anolog instead of Pt/air-RE. Thus, it would be a great advancement if the necessity of Pt/air-RE for the presently-used potentiometric oxygen sensors could be avoided. So far, several metal/metal oxide (M/MO) couples have been reported to be used as an internal solid-RE in the YSZ-based potentiometric oxygen sensor [11-14]. In this case, M/MO solid-RE should be always hermetically sealed inside a YSZ tube or on a YSZ layer. The oxygen pressure generated from reaction (2) varies with temperature and can be calculated from van't Hoff isochore equation.

$$
\mathrm{M}_{\mathrm{x}} \mathrm{O}_{\mathrm{y}} \rightleftarrows \mathrm{xM}+\frac{\mathrm{y}}{2} \mathrm{O}_{2}
$$

However, tight sealing against oxygen penetration to M/MO solid-RE reflecting the long-term sensor's stability at high temperature is still a highly-challenging issue.

We have recently proposed a concept of a novel all-solid-state RE, which, in general, should be (i) completely insensitive to various exhaust gases, (ii) absolutely inert to change in oxygen concentration over a wide range and (iii) highly stable at elevated temperatures and in a harsh environment. The second criterion, i.e. the absolute insensitivity to change in oxygen concentration, seems to be much more preferable, because it can allow to avoid the necessity of tight sealing of RE and to give the opportunity to minimize the sensor structure. Thus, we 
have reported the YSZ-based oxygen sensor using the new solid-state $\mathrm{NiMn}_{2} \mathrm{O}_{4}-\mathrm{RE}$ [15]. The obtained results have been found to be very promising and indicated that the Mn-based oxides have a great potential for replacing the conventional Pt/air-RE. Rajabbeigi et al. $[16,17]$ have reported on the sensors attached with the ceria-based RE, but the sensors exhibited the rather lower emf change at around the stoichiometric $\mathrm{A} / \mathrm{F}$ ratio, in comparison with that using the conventional Pt/air-RE.

In an effort to find a solid-state RE which is more insensitive to oxygen, we have lately examined various Mn-based oxides. As a result, $\mathrm{Mn}_{2} \mathrm{O}_{3}$ used as SE in the tubular YSZ-based sensor (vs. the inner Pt-RE) was found to be insensitive to most of exhaust gases examined here as well as to the change in oxygen concentration. Thus, we report here the sensing performances of tubular and planar-like rod-type YSZ-based sensors attached with $\mathrm{Mn}_{2} \mathrm{O}_{3}-\mathrm{RE}$ as an equilibrium-potential-type oxygen sensor, a normalized $\mathrm{A} / \mathrm{F}$ ratio $(\lambda)$ sensor and a mixed-potential-type gas sensor.

\section{Experimental}

\subsection{Fabrication of sensor devices}

The schematic views of the fabricated tubular and planar-like rod-type YSZ-based sensors are shown in Figs. 1 (a) and (b), respectively. The tubular sensor was fabricated by using a commercial one-end-closed YSZ tube (8 mol.\% $\mathrm{Y}_{2} \mathrm{O}_{3}$-doped $\mathrm{ZrO}_{2}$, Nikkato, Japan). The physical dimensions of the tube were $300 \mathrm{~mm}$ in length, 5 and $8 \mathrm{~mm}$ in inner and outer diameter, respectively. At the first setout, each of the sixteen kinds of Mn-based oxide powders $\left(\mathrm{SmMnO}_{3}, \mathrm{CuCrMnO}_{4}, \mathrm{NdMnO}_{3}, \mathrm{MgMnO}_{3}, \mathrm{CoMnO}_{3}, \mathrm{LaMnO}_{3}, \mathrm{SrMn}_{2} \mathrm{O}_{4}\right.$, $\mathrm{CrMn}_{2} \mathrm{O}_{4}, \mathrm{NiMn}_{2} \mathrm{O}_{4}, \mathrm{CrMnO}_{3}, \mathrm{CuFeMn}_{2} \mathrm{O}_{4}, \mathrm{Cr}_{2} \mathrm{MnO}_{4}, \mathrm{MnO}, \mathrm{Mn}_{3} \mathrm{O}_{4}, \mathrm{MnO}_{2}$ and $\mathrm{Mn}_{2} \mathrm{O}_{3}$ ) was 
thoroughly mixed with $\alpha$-terpineol to make a uniform paste. Each paste obtained was applied on the outer surface of YSZ tube to form a belt-like oxide layer of $3 \mathrm{~mm}$ wide. After drying at $130^{\circ} \mathrm{C}$, each YSZ tube attached with each of the Mn-based oxides was sintered at high temperature in air so as to form the outer solid-state Mn-based oxide SE. Then, the dimensionally-same Pt layer was additionally formed by applying commercial Pt paste (TR7907, Tanaka Kikinzoku Co., Ltd., Japan) on the outer surface of the YSZ tube attached with each of the pre-sintered Mn-based oxide SEs. In the case of $\mathrm{Mn}_{2} \mathrm{O}_{3}$-SE, a commercial $\mathrm{Au}$ paste was also applied on the outer surface of the YSZ tube (Fig. 1 (a)). The Pt paste was also applied on the inner surface of the YSZ tube at its closed end. Finally, this YSZ tube was fired at $1000^{\circ} \mathrm{C}$ for $2 \mathrm{~h}$ in air to fabricate the outer Pt- and Au-SEs as well as the inner Pt-RE.

To fabricate the planar-like rod-type YSZ-based sensor (Fig. 1 (b)), $\mathrm{Mn}_{2} \mathrm{O}_{3}, \mathrm{Pt}$ and $\mathrm{Au}$ pastes were applied on the surface of a commercial YSZ rod $(10 \mathrm{~mm}$ in length and $3 \mathrm{~mm}$ in diameter, Nikkato, Japan). The width of the belt-like layers was about 2-3 mm. The sensor was fabricated by using the same two-step sintering procedure, as mentioned above. In this

case, the layer fabricated by using the $\mathrm{Mn}_{2} \mathrm{O}_{3}$ paste was considered as $\mathrm{RE}\left(\mathrm{Mn}_{2} \mathrm{O}_{3}-\mathrm{RE}\right)$, whereas the fabricated Pt and Au layers were used as SE.

\subsection{Evaluation of sensing properties}

Each of the fabricated tubular and planar-like rod-type YSZ-based sensors was assembled in a quartz tube in the close vicinity of a gas inlet (Fig. 1) and connected to a conventional gas-flow apparatus equipped with a high-temperature electric furnace. The evaluation of gassensing characteristics were carried out in the temperature range of $400-800^{\circ} \mathrm{C}$.

In the case of the tubular sensor, each of the outer Mn-based oxide SEs was exposed to the humidified base gas (21 vol.\% $\mathrm{O}_{2}+$ water vapor $+\mathrm{N}_{2}$ balance) or the sample gas containing 
various oxygen concentrations in the range of $0.05-21$ vol.\% (+ water vapor $+\mathrm{N}_{2}$ balance). The concentration of water vapor was fixed at 5 vol.\% except for the examination of water vapor effect on gas-sensing characteristics. The inner Pt-RE was always exposed to the ambient atmospheric air (Pt/air-RE). The difference in potential (emf) between each of the outer SEs connected to the positive terminal of a digital electrometer (R8240, Advantest, Japan) and the inner Pt/air-RE connected to the negative terminal was measured as a sensing signal.

As for the rod-type sensor, the Pt- and Au-SEs as well as $\mathrm{Mn}_{2} \mathrm{O}_{3}-\mathrm{RE}$ were simultaneously exposed to the base gas or the sample gas. The examination of cross sensitivities to various gases was carried out by using each of gases $\left(\mathrm{CO}, \mathrm{NO}, \mathrm{NO}_{2}, \mathrm{NH}_{3}, \mathrm{H}_{2}, \mathrm{CH}_{4}, \mathrm{C}_{3} \mathrm{H}_{4}, \mathrm{C}_{3} \mathrm{H}_{6}, \mathrm{C}_{3} \mathrm{H}_{8}\right.$, $100 \mathrm{ppm}$ each) diluted with the humidified base gas. Here, the emf signal between Pt- or AuSE connected to the positive terminal of electrometer and $\mathrm{Mn}_{2} \mathrm{O}_{3}-\mathrm{RE}$ connected to the negative one was recorded as a sensing signal. The gas sensitivity ( $\Delta e m f)$ was defined as a difference between the emf value of the sensor in the sample gas (emf $\left.f_{\text {sample gas }}\right)$ and that in the base gas (emf $\left.f_{\text {base gas }}\right)$.

The evaluation of both fabricated devices as an A/F sensor was performed in the range of a normalized $\mathrm{A} / \mathrm{F}$ ratio $(\lambda)$ of $0.85-1.15$. Here, the constant concentration $(2000 \mathrm{ppm})$ of propane $\left(\mathrm{C}_{3} \mathrm{H}_{8}\right)$ was used as a fuel gas and was oxidized just before the sensing device by utilizing an oxidation catalyst in accordance with the following reaction

$$
\mathrm{C}_{3} \mathrm{H}_{8}+5 \mathrm{O}_{2} \longrightarrow 3 \mathrm{CO}_{2}+4 \mathrm{H}_{2} \mathrm{O}
$$

In this case, the normalized $\lambda$ value can be defined as follows,

$$
\lambda=\left\{C\left(\mathrm{O}_{2}\right) / C\left(\mathrm{C}_{3} \mathrm{H}_{8}\right)\right\} / 5 \text { (Here, } C \text { means gas concentration.) }
$$

The different $\lambda$ values can be obtained by changing the oxygen concentration in the sample gas. The stoichiometric point $(\mathrm{A} / \mathrm{F}=5)$ is characterized as $\lambda=1$. 


\section{Results and Discussion}

\subsection{Performances of tubular sensor}

Firstly, each of sixteen kinds of Mn-based oxides was examined in the tubular YSZ-based sensor. In each case, the fabricated outer Mn-based oxide layer was assigned as SE and measured with respect to the inner Pt/air-RE (Fig. 1 (a)). The obtained results of sensitivity to 0.1 vol. $\% \mathrm{O}_{2}$ at $600^{\circ} \mathrm{C}$ are shown in Fig. 2. Here, the sensitivity ( $\left.\Delta e m f\right)$ is defined as the difference between emf of the sensor in 0.1 vol. $\% \mathrm{O}_{2}$ and that in the base gas $\left(21\right.$ vol. $\left.\% \mathrm{O}_{2}\right)$. The sensitivity depended on the kind of Mn-based oxide SE. Some of them (e.g. $\mathrm{Cr}_{2} \mathrm{MnO}_{4}$, $\mathrm{Mn}_{3} \mathrm{O}_{4}, \mathrm{Mn}_{2} \mathrm{O}_{3}$ etc.) gave the smaller emf value of less than $2 \mathrm{mV}$, while some of them (e.g. $\mathrm{SmMnO}_{3}, \mathrm{CuCrMnO}_{4}, \mathrm{NdMnO}_{3}$ etc.) gave rather large value of more than $10 \mathrm{mV}$. Among them, $\mathrm{Mn}_{2} \mathrm{O}_{3}$-SE showed the lowest oxygen sensitivity (less than $0.3 \mathrm{mV}$ ) under the present condition.

Thus, the sensing characteristics of the tubular sensor attached with Pt- , $\mathrm{Au}-$ and $\mathrm{Mn}_{2} \mathrm{O}_{3^{-}}$ SEs were examined. Figure 3(a) shows the dependence of emf on the oxygen concentration in the range of $0.05-21$ vol. $\%$ for the tubular sensor operated at $550^{\circ} \mathrm{C}$. It is seen that, in the case of Pt-SE, emf varied linearly with the logarithm of oxygen concentration. The slope of the linear relationship gives $39.7 \mathrm{mV} /$ decade. Based on this slope value, the number of electrons (n) participated to equilibrium electrochemical reaction of oxygen can be calculated to be 4.1 These values are consistent with the theoretical ones $(40.8 \mathrm{mV} /$ decade, $\mathrm{n}=4.0)$ calculated by Nernst equation (1) for a YSZ-based oxygen concentration cell attached with Pt-SE and Pt/airRE. In the case of Au-SE, the slope value (29.2 mV/decade) and $n$ value $(n=5.6)$ are deviated from the theoretical ones. This result can be attributable to the low electrochemical catalytic activity of $\mathrm{Au}$ to gaseous oxygen. As for $\mathrm{Mn}_{2} \mathrm{O}_{3}-\mathrm{SE}$, the emf response at this temperature is 
totally independent of oxygen concentration in the examined range, as also shown in Fig. 3 (a). Then, to investigate further response behavior to oxygen for all these SEs, the slope value of the relationship between emf and the logarithm of oxygen concentration was examined in the temperatures range of $400-800^{\circ} \mathrm{C}$. The obtained results are given in Fig. 3 (b). The sensor attached with the outer Pt-SE shows the linear relationship between the slope and the operating temperature examined. This linear behavior is also obeying Nernst equation (1). In the case of Au-SE, the temperature dependence of the slope is non-linear and nonreproducible. On the contrary to both Pt- and Au-SEs, the outer $\mathrm{Mn}_{2} \mathrm{O}_{3}$-SE was found to be almost insensitive to change in the oxygen concentration at temperatures below or equal to $550^{\circ} \mathrm{C}$. In the temperature range of $600-800^{\circ} \mathrm{C}$, the slope value increased rapidly with increasing temperature. Such behavior of the tubular sensor against oxygen implies that $\mathrm{Mn}_{2} \mathrm{O}_{3}$ can be potentially used for fabrication of solid-RE applicable to a planar oxygen sensor operated at $\mathrm{T}<600^{\circ} \mathrm{C}$.

\subsection{Planar-like rod-type sensor using $\mathrm{Mn}_{2} \mathrm{O}_{3}-\mathrm{RE}$}

Based on the above-mentioned results, the tubular YSZ-based sensor was miniaturized and re-configured to the planar-like geometry by the use of a small YSZ-rod (Fig. 1 (b)). Here, all three electrodes, Pt- and Au-SEs as well as $\mathrm{Mn}_{2} \mathrm{O}_{3}$-RE, were simultaneously exposed to either of the base gas or the sample gas. More specifically, Pt-SE was used to evaluate the behavior of planar oxygen sensor, while Au-SE was evaluated so as to estimate its gas sensing performances vs. $\mathrm{Mn}_{2} \mathrm{O}_{3}$-RE. Figure 4 (a) shows the response transients to various oxygen concentrations in the range of $0.05-21$ vol.\% for the present type of sensor operating at $550^{\circ} \mathrm{C}$ under the wet condition. It is seen that the emf value of the sensor coupled with Pt-SE and $\mathrm{Mn}_{2} \mathrm{O}_{3}-\mathrm{RE}$ changes rapidly from a stable base level upon switching from the base gas to 
the sample gas and then reaches a steady-state value in a short time. The back switching to the base gas resulted in quick return to the original emf value. It is noted that the emf response to even rather low concentration $(0.05$ vol. $\%)$ of oxygen is still stably high. Moreover, even though our gas-flow system was not optimized to obtain the fastest response, the $90 \%$ response/recovery time for the present sensor was about 12 s. Figure 4 (b) shows the dependence of $\Delta e m f\left(=e m f_{\text {sample gas }}-e m f_{\text {base gas }}\right)$ on oxygen concentration at $550^{\circ} \mathrm{C}$ for the rodtype sensor using Pt-SE and $\mathrm{Mn}_{2} \mathrm{O}_{3}$-RE. The dependence of $\Delta e m f$ was found to show the perfect linearity with respect to the logarithm of oxygen concentration, obeying Nernst equation (1). It is of significant importance that the slope $(n=4.1)$ observed here is exactly same as that obtained for the tubular sensor (the outer Pt-SE vs. the inner Pt/air-RE) and consistent with the theoretical value $(n=4.0)$ for an equilibrium oxygen concentration cell.

The emf response to 5 vol. $\% \mathrm{O}_{2}$ for the present miniaturized planar sensor operated at $550^{\circ} \mathrm{C}$ was additionally examined in the wide range of water vapor (0-16 vol.\%). The obtained results (Fig. 4 (c)) indicated that the emf response was hardly affected by the change in water vapor. Thus, $\mathrm{Mn}_{2} \mathrm{O}_{3}$ - $\mathrm{RE}$ seems to possess a good stability both in dry and highly humid environment. This is an important result for a potential application of this kind of sensor in real harsh environments.

Figure 5 shows the emf responses to various gases $\left(\mathrm{C}_{3} \mathrm{H}_{8}, \mathrm{C}_{3} \mathrm{H}_{4}, \mathrm{C}_{3} \mathrm{H}_{6}, \mathrm{CH}_{4}, \mathrm{CO}, \mathrm{NO}, \mathrm{H}_{2}\right.$, $\mathrm{NH}_{3}, 100 \mathrm{ppm}$ each) at $550^{\circ} \mathrm{C}$ under the wet condition for the planar sensor attached with each of Pt- and Au-SE (vs. $\mathrm{Mn}_{2} \mathrm{O}_{3}-\mathrm{RE}$ ). It is seen that the sensor using a couple of Pt-SE and $\mathrm{Mn}_{2} \mathrm{O}_{3}-\mathrm{RE}$ was almost insensitive to each of the examined gases except for $\mathrm{H}_{2}$ and $\mathrm{NH}_{3}$. It should be, however, emphasized that the small responses to $\mathrm{H}_{2}$ and $\mathrm{NH}_{3}$ are not caused by the utilization of $\mathrm{Mn}_{2} \mathrm{O}_{3}$-RE. It was separately observed that the similar minor responses were also observed for the tubular sensor using Pt-SE and Pt/air-RE and no response were observed at all for the tubular sensor using $\mathrm{Mn}_{2} \mathrm{O}_{3}-\mathrm{SE}$ and $\mathrm{Pt} / \mathrm{air}-\mathrm{RE}$ at $550^{\circ} \mathrm{C}$ (not shown here). Thus, it 
can be confirmed that $\mathrm{Mn}_{2} \mathrm{O}_{3}-\mathrm{RE}$ (or $\mathrm{SE}$ ) is insensitive to various hazardous gases examined at $550^{\circ} \mathrm{C}$. On the other hand, the sensor attached with a couple of $\mathrm{Au}-\mathrm{SE}$ and $\mathrm{Mn}_{2} \mathrm{O}_{3}-\mathrm{RE}$ exhibited large responses to $\mathrm{CO}, \mathrm{H}_{2}$ and unsaturated HCs. Such a behavior is typical for the mixed-potential-type YSZ-based sensors (using Au-SE and Pt-RE) performed in either tubular or planar configuration [18-20].

\section{$3.3 \mathrm{~A} / \mathrm{F}$ ratio $(\lambda)$ sensors}

Figure 6 shows the dependence of emf on the normalized A/F ratio $(\lambda)$ for the fabricated (a) tubular and (b) planar-like rod-type YSZ-based sensors operated at $550^{\circ} \mathrm{C}$ under the wet condition. The tubular sensor attached with the outer $\mathrm{Mn}_{2} \mathrm{O}_{3}-\mathrm{SE}$ and the inner Pt/air-RE was found to be insensitive to the change in $\mathrm{A} / \mathrm{F}$ ratio, indicating the excellent stability of $\mathrm{Mn}_{2} \mathrm{O}_{3^{-}}$ RE even at such an extremely low oxygen partial pressure (rich region, $\lambda<1$ ). Furthermore, it is seen that both of the tubular (the outer Pt-SE vs. the inner Pt/air-RE) and rod-type (Pt-SE vs. $\mathrm{Mn}_{2} \mathrm{O}_{3} \mathrm{RE}$ ) sensors show almost same behavior. When $\lambda$ decreases from lean $(\lambda>1)$ to rich $(\lambda<1)$ region, the $\lambda$ dependence of emf exhibited a sharp transition from about $-100 \mathrm{mV}$ to $-700-800 \mathrm{mV}$ with the peak inflection point at around $\lambda=1$ (stochiometric). On the other side, the tubular and rod-type sensors using Au-SE did not exhibit such a sharp transition, probably due to much lower catalytic activity of Au against the electrochemical reaction involving oxygen.

Figure 7 depicts the emf response transients upon switching the sample gas from lean $(\lambda=1.1)$ to rich $(\lambda=0.9)$ and vice versa conditions for the rod-type sensor using Pt-SE and $\mathrm{Mn}_{2} \mathrm{O}_{3}-\mathrm{RE}$ operated at $550^{\circ} \mathrm{C}$. The emf value changed rapidly from about $-80 \mathrm{mV}$ to $-720 \mathrm{mV}$ and backward at lean-rich and rich-lean transition, respectively. Such a quick change of emf was repeated rather stably in ten-time cycles examined. This result is of vital importance, 
confirming the high stability of $\mathrm{Mn}_{2} \mathrm{O}_{3}-\mathrm{RE}$ under both of lean (oxygen-rich) and rich (oxygenlean) conditions.

\section{Conclusions}

Among the different Mn-based oxides tested as SE in tubular YSZ-based sensor, $\mathrm{Mn}_{2} \mathrm{O}_{3^{-}}$ SE was found to be insensitive to oxygen as well as to most common hazardous or polluting gases, when the operating temperature was below or equal to $550^{\circ} \mathrm{C}$. The tubular YSZ-based sensor was successfully miniaturized to planar-like rod-type one, in which the fabricated $\mathrm{Pt}$ and $\mathrm{Au}$ layers were used as SEs and the $\mathrm{Mn}_{2} \mathrm{O}_{3}$ layer was assigned as $\mathrm{RE}$. The planar sensor using a couple of Pt-SE and $\mathrm{Mn}_{2} \mathrm{O}_{3}-\mathrm{RE}$ also showed negligible responses to oxidizing/reducing gases at $550^{\circ} \mathrm{C}$ under the wet condition. The present sensor gave excellent sensitivity to oxygen in the examined concentration range of $0.05-21 \mathrm{vol} . \%$. The sensitivity (Aemf) varied logarithmically with oxygen concentration, obeying Nernst equation. In addition, the planar-like rod-type sensor exhibited the excellent performances as an A/F ratio ( $\lambda$ ) sensor at $550^{\circ} \mathrm{C}$. Thus, based on the obtained results, it seems that solid-state $\mathrm{Mn}_{2} \mathrm{O}_{3}-\mathrm{RE}$ can be potentially utilized in miniaturized planar YSZ-based potentiometric oxygen/AFR sensors. However, the working mechanism of $\mathrm{Mn}_{2} \mathrm{O}_{3}-\mathrm{RE}$ is now under investigation.

\section{Acknowledgements}

This work was partially supported by Kyushu University Global-COE Program on "Novel Carbon Resource Sciences" and Grant-in-Aid for Scientific Research (B), (No. 22350095) from MEXT, Japan. 


\section{References}

[1] http://epp.eurostat.ec.europa.eu/statistics_explained/index.php (European Union, 2006); http://www.pewclimate.org/technology/overview/transportation (USA, 2008).

[2] S. Matsumoto, Recent advances in automobile exhaust catalysts, Catal. Today 90 (2004) 183-190.

[3] M. Bowker, Automotive catalysis studied by surface science, Chem. Soc. Rev. 37 (2008) 2204-2211.

[4] T. Takeuchi, Oxygen sensors, Sens. Actuators. 14 (1988) 109-124.

[5] E. Ivers-Tiffée, K. H. Härdtl, W. Menesklou, J. Riegel, Principles of solid state oxygen sensors for lean combustion gas control, Electrochim. Acta 47 (2001) 807-814.

[6] J. Riegel, H. Neumann, H.-M. Wiedenmann, Exhaust gas sensors for automotive emission control, Solid State Ionics 152-153 (2002) 783-800.

[7] J.-H. Lee, Review on zirconia air-fuel ratio sensors for automotive applications, J. Mater. Sci. 38 (2003) 4247- 4257.

[8] R. Ramamoorthy, P. K. Dutta, S. A. Akbar, Oxygen sensors: Materials, methods, designs and applications, J. Mater. Sci. 38 (2003) 4271-4282.

[9] R. Moos, A brief overview on automotive exhaust gas sensors based on electroceramics, Inter.Appl. Ceram. Technol. 2 (2005) 401-405.

[10] A. G. Mortimer, G. P. Reed, Development of a robust electrochemical oxygen sensor, Sens. Actuators B: Chem. 24-25 (1995) 328-335.

[11] H. Kaneko, T. Okamura, H. Taimatsu, Characterization of zirconia oxygen sensors with a molten internal reference for low-temperature operation, Sens. Actuators B: Chem. 93 (2003) 205- 208. 
[12] H. Kaneko, T. Okamura, H. Taimatsu, Y. Matsuki, H. Nishida, Performance of a miniature zirconia oxygen sensor with a $\mathrm{Pd}-\mathrm{PdO}$ internal reference, Sens. Actuators B: Chem. 108 (2005) 331-334.

[13] S. Colominas, J. Abella and L. Victori, Characterisation of an oxygen sensor based on $\mathrm{In} / \mathrm{In}_{2} \mathrm{O}_{3}$ reference electrode, J. Nucl. Mater. 335 (2004) 260-263.

[14] R. Radhakrishnan, A. V. Virkar, S. C. Singhal, G. C. Dunham, O. A. Marina, Design, fabrication and characterization of a miniaturized series-connected potentiometric oxygen sensor, Sens. Actuators B: Chem. 105 (2005) 312-321.

[15] N. Miura, S. Nakakubo, D. Terada, Y. Shimamoto, Gas-insensitive oxide material as a new-type solid reference electrode for planar oxygen sensor based on YSZ, Abstract of SSI-15, p.586 (2005).

[16] N. Rajabbeigi, B. Elyassi, A. Khodadadi, S. S. Mohajerzadeh, M. Sahimi, A novel miniaturized oxygen sensor with solid-state ceria-zirconia reference, Sens. Actuators B: Chem. 100 (2004) 139-142.

[17] N. Rajabbeigi, B. Elyassi, A. A. Khodadadi, S. Mohajerzadeh, Y. Mortazavi, M. Sahimi, Oxygen sensor with solid-state $\mathrm{CeO}_{2}-\mathrm{ZrO}_{2}-\mathrm{TiO}_{2}$ reference, Sens. Actuators B: Chem. 108 (2005) 341-345.

[18] T. Hibino, Y. Kuwahara, S. Wang, S. Kakimoto, M. Sano, Nonideal electromotive force of zirconia sensors for unsaturated hydrocarbon gases, Electrochem. Solid-state Lett. 1 (4) (1998) 197-199.

[19] R. Mukundan, E. L. Brosha, D. R. Brown, F. H. Garzon, A mixed-potential sensor based on a $\mathrm{Ce}_{0.8} \mathrm{Gd}_{0.2} \mathrm{O}_{1.9}$ electrolyte and platinum and gold electrodes, J. Electrochem. Soc. 147 (4) (2000) 1583-1588. 
[20] V. V. Plashnitsa, P. Elumalaia, Y. Fujio, N. Miura, Zirconia-based electrochemical gas sensors using nano-structured sensing materials aiming at detection of automotive exhausts, Electrochim. Acta 54 (2009) 6099-6106. 


\section{Biographies}

Norio Miura has been a professor at Kyushu University, Japan since 1999. He received BE degree in Applied Chemistry in 1973, ME degree in 1975 from Hiroshima University, Japan and $\mathrm{PhD}$ degree in Engineering in 1980 from Kyushu University. His current research concentrates on development of high-performance chemical sensors (e.g. solid-state sensors for environmental gases and SPR immunosensors) as well as new functional materials for electrochemical supercapacitors and selective oxygen separators.

Han Jin received his BSc degree in Applied Chemistry from East China Institute of Technology in 2007. After that he joined University of Science and Technology of China for MSc study in Catalytic Chemistry. In 2009, he received CSC financial support from Chinese Government for his $\mathrm{PhD}$ study in Interdisciplinary Graduate School of Engineering Sciences, Kyushu University. Currently, he is a doctor course student in Kyushu University and his research interests are focused on the development of high-performance gas-sensing devices based on stabilized zirconia and oxide sensing-electrodes.

Ryotaro Wama received his MSc degree in 2006 and $\mathrm{PhD}$ degree in 2009 from Interdisciplinary Graduate School of Engineering Sciences, Kyushu University, Japan. Currently, he is employed in Tokuyama Corp., Japan.

Shouhei Nakakubo received his MSc degree from Interdisciplinary Graduate School of Engineering Sciences, Kyushu University, Japan in 2006. Currently, he is employed in Kobe Steel Ltd., Japan. 
Perumal Elumalai received his MSc degree in Chemistry from Muthurangam Govt. Arts College, Vellore, India in 1997 and $\mathrm{PhD}$ degree from the Solid State \& Structural Chemistry Unit, Indian Institute of Science, Bangalore, India in 2004. During 2004-2009, he worked as a post-doctoral fellow in Arts, Science and Technology Center for Cooperative Research, Kyushu University, Japan. Currently, he is Assistant Professor in School of Chemistry, Department of Materials Science, Madurai Kamaraj University, Madurai, India. His research interests are on high temperature gas sensors, alkaline and Li-ion batteries, supercapacitors, electrocatalysis, nanomaterials and solid-state electrochemistry.

Vladimir V. Plashnitsa received his MSc degree in Electrochemical Engineering from the Vyatka State Technical University, Russia in 1997 and PhD degree in Materials Science (Dr. rer. nat.) from the Max-Planck-Institute for Metal Research, Germany in 2004. Currently, he is Research Assistant Professor of Research and Education Center of Carbon Resources, Kyushu University, Japan. His research interests concentrate on gas sensors based on nanostructured hetero-junction interface and nanocomposites as well as on new functional materials for solid-state gas sensing. 


\section{Figure Captions}

Fig. 1 Schematic views and photos for the fabricated (a) tubular and (b) planar-like rod-type YSZ-based sensors.

Fig. 2 Difference between emf in 0.1 vol. $\% \mathrm{O}_{2}$ and that in 21 vol. $\% \mathrm{O}_{2}$ for the tubular YSZbased sensor attached with each of Mn-based oxide SEs operated at $600^{\circ} \mathrm{C}$.

Fig. 3 (a) Dependence of emf on the logarithm of oxygen concentration and (b) slope for oxygen concentration dependence of emf evaluated at various operating temperatures, for the tubular sensor attached with the outer Pt-, Au- and $\mathrm{Mn}_{2} \mathrm{O}_{3}$-SEs (vs. the inner Pt/air-RE).

Fig. 4 (a) Response transients to various oxygen concentrations, (b) dependence of sensitivity $(\Delta e m f)$ on the logarithm of oxygen concentration and (c) effect of water vapor on emf response to 5 vol.\% $\mathrm{O}_{2}$, for the planar-like rod-type YSZ-based sensor using a couple of Pt-SE and $\mathrm{Mn}_{2} \mathrm{O}_{3}-\mathrm{RE}$ operated at $550^{\circ} \mathrm{C}$.

Fig. 5 Response transients to various gases (100 ppm each) at $550^{\circ} \mathrm{C}$ under the wet condition ( 5 vol. $\% \mathrm{H}_{2} \mathrm{O}$ ) for the rod-type sensor using each of Pt- and $\mathrm{Au}-\mathrm{SEs}$ (vs. $\mathrm{Mn}_{2} \mathrm{O}_{3}-\mathrm{RE}$ ).

Fig. 6 Dependence of emf on the normalized A/F ratio ( $\lambda$ ) for (a) tubular and (b) rod-type sensors operated at $550^{\circ} \mathrm{C}$ in the presence of 5 vol. $\%$ water vapor.

Fig. 7 Repeated response transients of rod-type sensor using a couple of Pt-SE and $\mathrm{Mn}_{2} \mathrm{O}_{3^{-}}$ $\mathrm{RE}$ operated at $550^{\circ} \mathrm{C}$ under lean $(\lambda=1.1)$ and rich $(\lambda=0.9)$ conditions. 


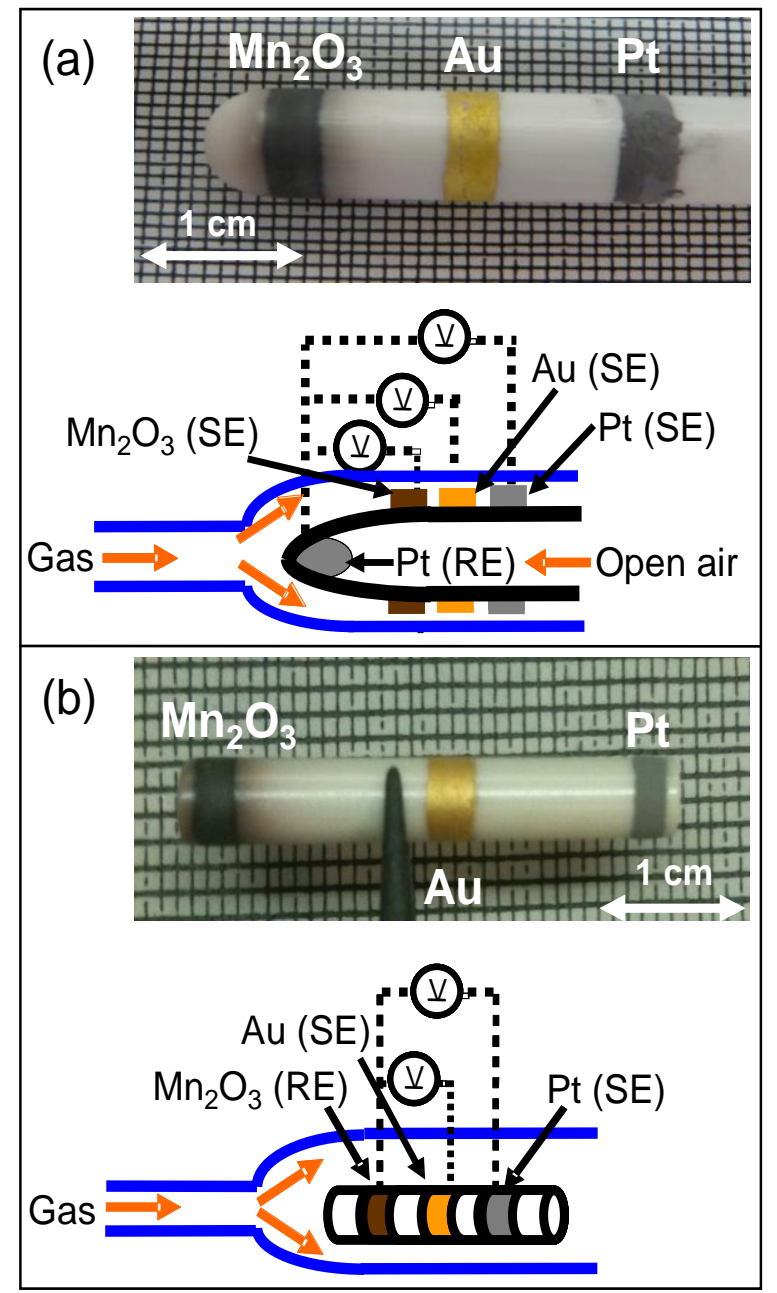

Figure 1 


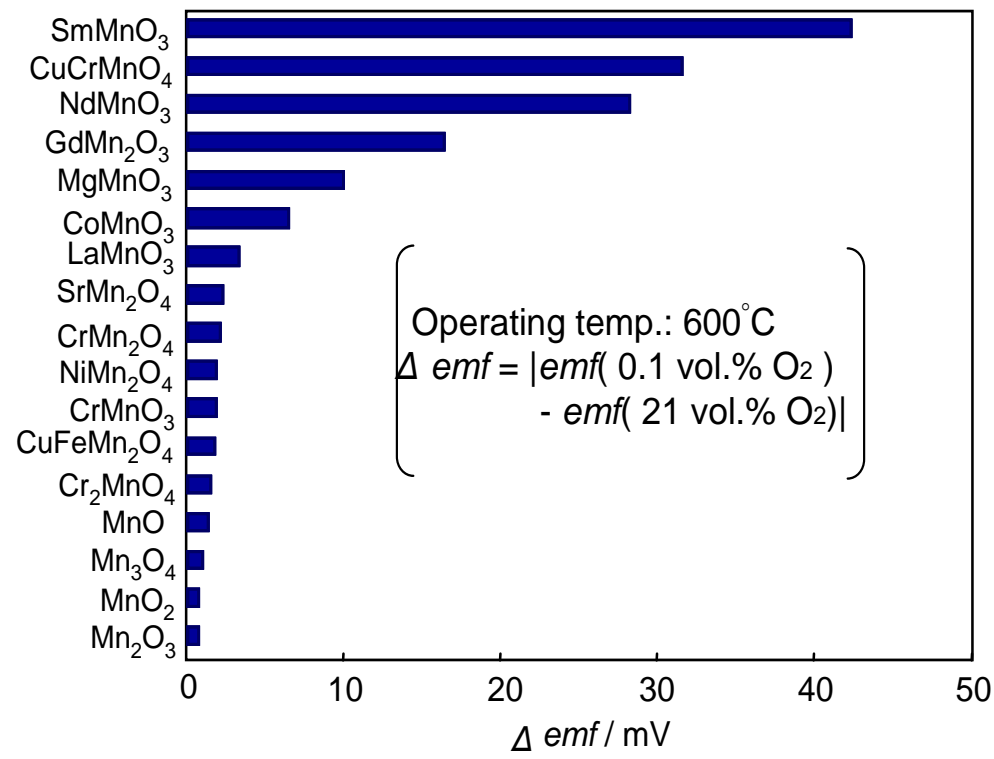

Figure 2 

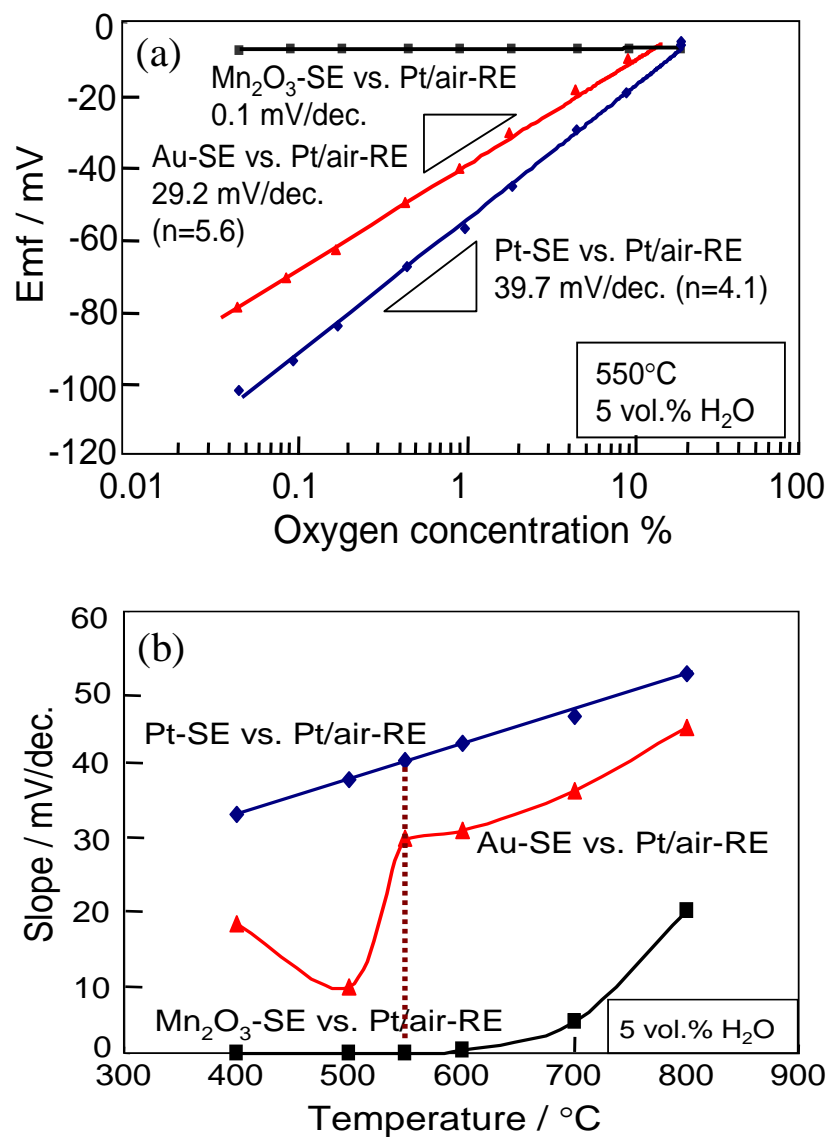

Figure 3 

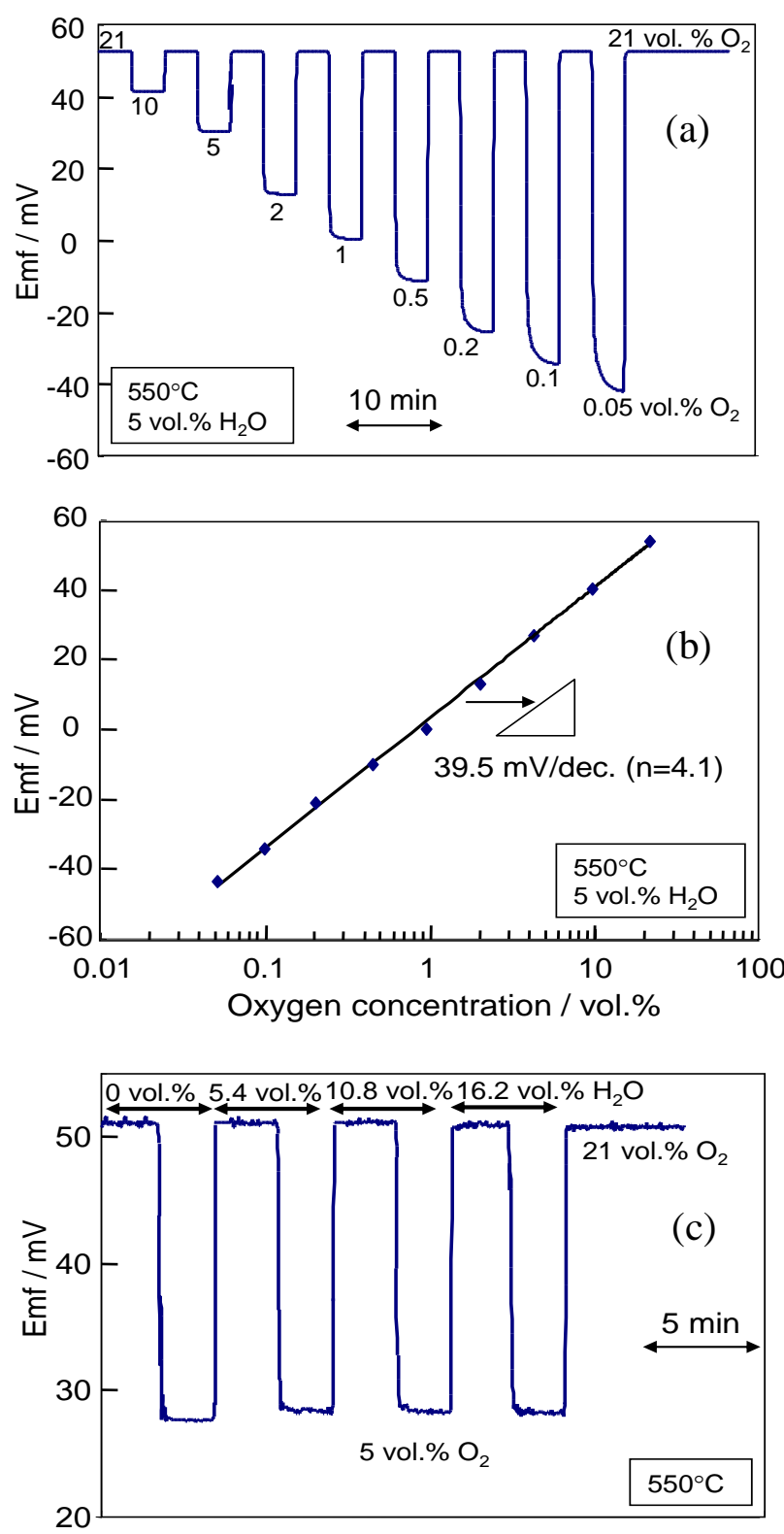

Figure 4 


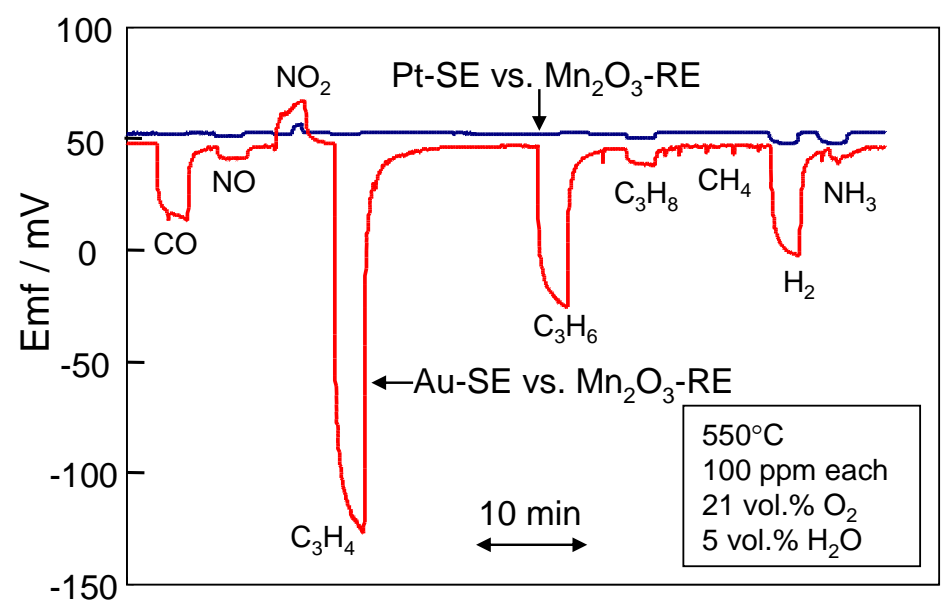

Figure 5

Page 23 of 25 

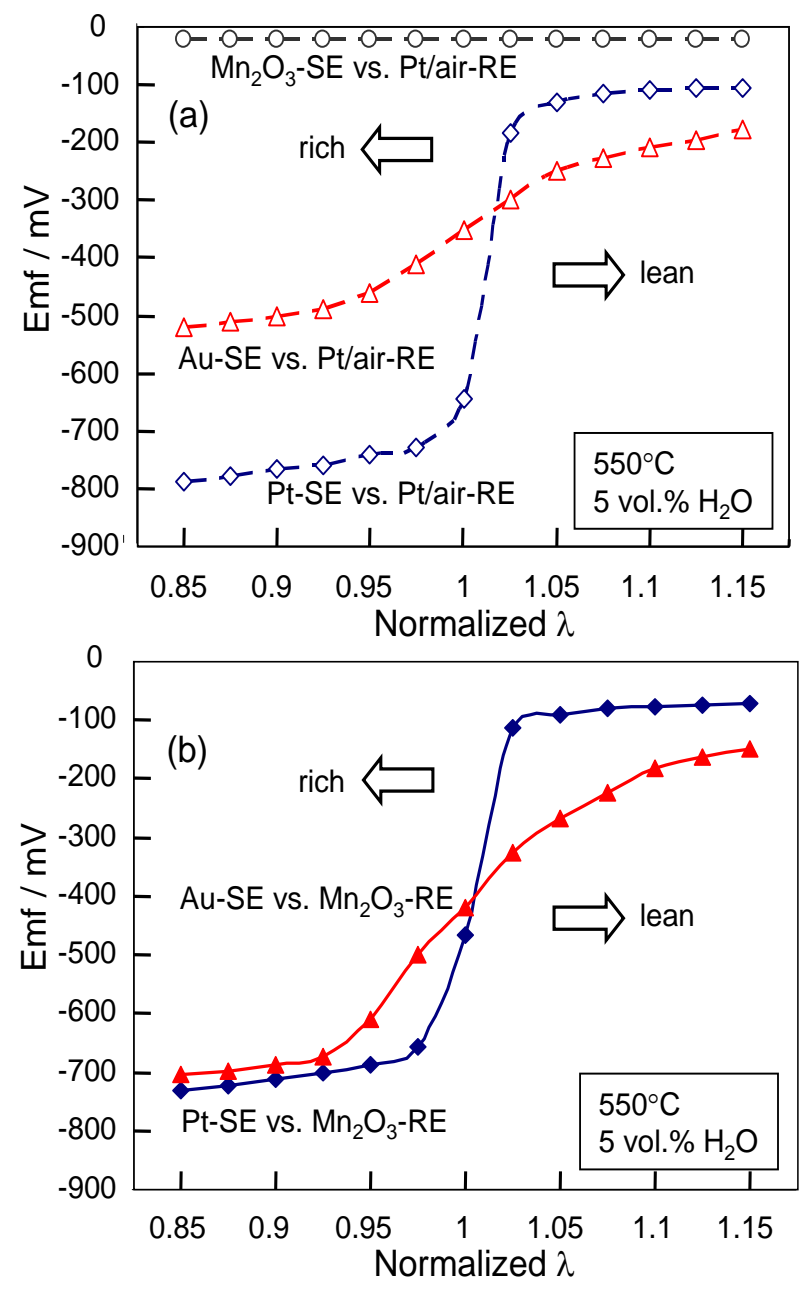

Figure 6 


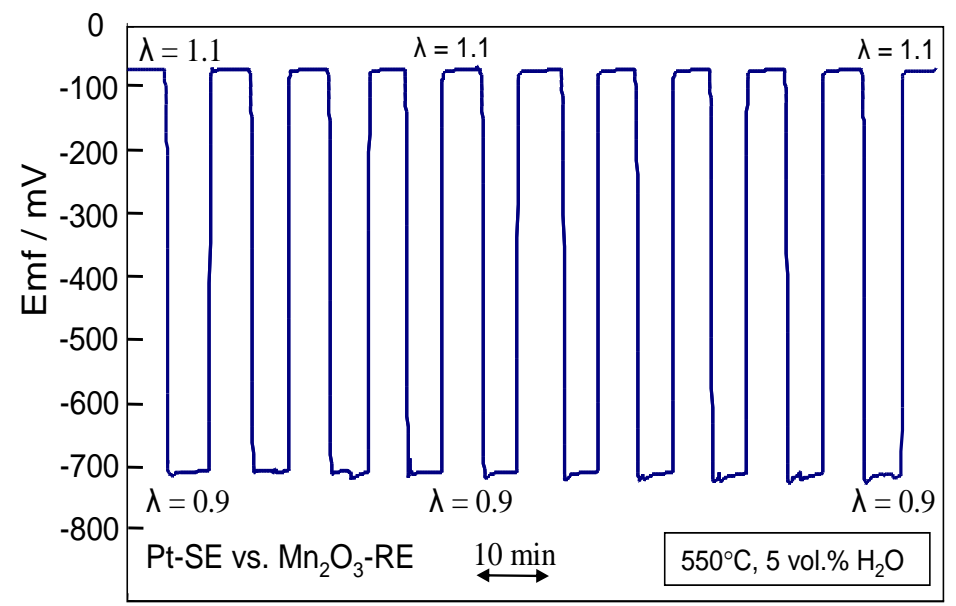

Figure 7

Page 25 of 25 